\title{
Preclinical Evaluation of Reconsolidation Blockade by Clonidine as a Potential Novel Treatment for Posttraumatic Stress Disorder
}

\author{
Karine Gamache*,', Roger K Pitman ${ }^{2}$ and Karim Nader' \\ 'Department of Psychology, McGill University, Montreal, QC, Canada; '2Department of Psychiatry, Massachusetts General Hospital and Harvard \\ Medical School, Boston, MA, USA
}

\begin{abstract}
Exposure to traumatic events can lead to posttraumatic stress disorder (PTSD). Current PTSD treatments typically only produce partial improvement. Hence, there is a need for preclinical research to identify new candidate drugs and to develop novel therapeutic approaches. Animal studies have indicated that fear memories can be weakened by blocking restabilization after retrieval, a process known as reconsolidation. Furthermore, evidence suggests that there are important alterations of the noradrenergic system in PTSD, and hence it may be of interest to study drugs that target this pathway. Here, we investigated the efficacy of clonidine, an $\alpha_{2}$-adrenoreceptor agonist, to block reconsolidation in an animal model of persistent traumatic memories. Using an auditory fear conditioning paradigm in rats, we tested the efficacy of clonidine to weaken fear memory retention when administered systemically after retrieval. We evaluated dosage, number of treatments, and specificity in reconsolidation blockade. We found that postretrieval administration of clonidine disrupts fear-related memories in a dose-dependent manner and that two treatments are sufficient for maximal memory impairment. Furthermore, we determined that this effect is long lasting and specific to reconsolidation processes as shown by the selectivity to affect reactivated memories and the absence of spontaneous recovery and of postreactivation short-term memory impairment. Our results demonstrate the efficacy of systemic administration of clonidine following retrieval to persistently disrupt fear memory retention through reconsolidation blockade. This study provides important preclinical parameters for future therapeutic strategies involving clonidine to block reconsolidation as a novel treatment for PTSD symptoms.
\end{abstract}

Neuropsychopharmacology (2012) 37, 2789-2796; doi:I0.1038/npp.2012.145; published online 8 August 2012

Keywords: clonidine; memory; reconsolidation; fear conditioning; $\alpha 2$-adrenoreceptor agonist; posttraumatic stress disorder

\section{INTRODUCTION}

In a substantial minority of individuals, experiencing a traumatic event can lead to posttraumatic stress disorder (PTSD). This condition is characterized by several symptoms including irritability, hypervigilance, avoidance behaviors, intrusive memories, and frequent re-experiencing of the traumatic event through nightmares and flashbacks. PTSD affects $10-20 \%$ of people who have experienced a traumatic event. It has a lifetime prevalence of $6.8 \%$ in the United States (Kessler et al, 2005). Current therapeutic strategies include psychotherapy and pharmacological treatments; however, only $60 \%$ of patients will be responsive to these treatments (Davidson et al, 2006; Onder et al, 2006) and only 20-30\% will achieve full remission (Berger et al, 2009). Consequently,

*Correspondence: K Gamache, Department of Psychology, McGill University, 1205 Docteur Penfield Avenue, Montreal, QC, H3A IB I Canada, Tel: + | 5 |4 398 3167, Fax: + | 5 |4 398 4896,

E-mail: karine.gamache@mcgill.ca

Received I June 2012; revised 9 July 2012; accepted I2 July 2012 there is a significant need to develop novel pharmacological approaches to reduce symptoms of PTSD.

A proposed therapeutic strategy involves the modification of memory reconsolidation processes. In order for a new memory to be retained, it has to be stabilized through a mechanism referred to as consolidation. When such a memory is retrieved (recalled), it becomes unstable again for a short period of time, at which point it is susceptible to modifications (Nader and Hardt, 2009). The memory is then restabilized (reconsolidated) in its modified state. In PTSD, flashbacks, nightmares, and recollection of intrusive memories allow the traumatic memory trace to be retrieved and then reconsolidated (Charney, 2004). Impairing reconsolidation of such memories may lead to their weakening and may consequently diminish PTSD symptoms.

In animal models, pharmacological interventions exploit the vulnerable state of a memory after recall in order to impair reconsolidation. Even though there is no animal model that recreates PTSD entirely, fear conditioning is known to model the fear that accompanies reminders of the traumatic event (Pitman et al, 1999; Siegmund and Wotjak, 
2006). Studies have shown that fear memories can be weakened by blocking the restabilization process with different drugs, such as protein synthesis inhibitors (Nader et al, 2000), $N$-methyl-D-aspartate (Ben Mamou et al, 2006), or adrenergic receptor antagonists (Przybyslawski et al, 1999; Debiec and Ledoux, 2004) and inhibitors of the mammalian target of rapamycin (Blundell et al, 2008; Jobim et al, 2012). A disadvantage of these pharmacological agents is that most of them are toxic, administered intracranially, and not approved for humans. In order to more easily extrapolate work in animal models to clinical trials, investigated drugs should be safe for human use.

Evidence suggests that among other physiological alterations, there is increased noradrenergic activity in PTSD patients (Southwick et al, 1997, 1999; Boehnlein and Kinzie, 2007). Furthermore, it has been proposed that this hyperactivity is associated with hyperarousal and reexperiencing symptoms present in PTSD (Southwick et al, 1997; Boehnlein and Kinzie, 2007). Consequently, drugs that specifically target noradrenergic system hyperactivity and are safe for human use may be of clinical interest. One of those candidate drugs is the $\alpha_{2}$-adrenoreceptor agonist clonidine. The effect of clonidine on memory has been shown to be mediated through the $\alpha_{2}$-adrenoreceptor subtype (Galeotti et al, 2004). These receptors are located both pre- and post-synaptically. Clonidine is thought to act mainly at the presynaptic level by activating the $\alpha_{2}$-autoreceptor (Southwick et al, 1999; Wilens, 2006), which leads to inhibition of voltage-gated calcium channels and inhibition of norepinephrine release (Southwick et al, 1999; Gilsbach and Hein, 2011). Clinically, clonidine is used to induce sedation, analgesia, and hypotension (MacMillan et al, 1996; Lakhlani et al, 1997), as well as in the treatment of attention-deficit/hyperactivity disorder (Wilens, 2006). Additionally, a few open-label studies have shown beneficial effects of clonidine in treating some PTSD symptoms (Kinzie and Leung, 1989; Harmon and Riggs, 1996; Ziegenhorn et al, 2009), but none of these studies used clonidine specifically in combination with traumatic memory retrieval. In animal models, the use of clonidine has been found to produce memory impairments in step-down (GenkovaPapasova and Lazarova-Bakurova, 1988; Genkova-Papazova et al, 1997), shuttle box (Hawkins and Monti, 1979; Homayoun et al, 2003), and passive avoidance tasks (Galeotti et al, 2004); however, the use of clonidine to block memory reconsolidation has yet to be investigated.

The present study aims to examine the use of clonidine as a potential novel treatment for PTSD by testing its effects on the reconsolidation of a fear memory in rats. We investigated key parameters necessary to develop clinical studies involving reconsolidation blockade with clonidine. We determined the most effective dose through a dose-response curve, established the optimal number of treatments, and verified that the observed effects were reconsolidation specific.

\section{MATERIALS AND METHODS}

\section{Animals}

Equal numbers of male and female Sprague-Dawley rats weighing between 250 and $350 \mathrm{~g}$ (Harlan Laboratories,
Indianapolis, IN) were co-housed with ad libitum access to food and water. Rats were maintained on a $12 \mathrm{~h}$ light/dark cycle. All experiments were performed during the light (day) phase. All procedures were approved by McGill Animal Care Committee and complied with the Canadian Council for Animal Care guidelines.

\section{Drugs}

Clonidine hydrochloride (Sigma-Aldrich, Canada) was dissolved in sterile saline $(0.9 \% \mathrm{NaCl})$ to the final concentration $(50,100$, or $200 \mu \mathrm{g} / \mathrm{kg})$ and administered intraperitoneally at a volume of $1 \mathrm{ml} / \mathrm{kg}$ (Galeotti et al, 2004).

\section{Behavioral Procedure}

Rats underwent auditory fear conditioning, reactivation, and testing in the same experimental chamber to further resemble, in our animal model, a PTSD-like intrusive memory in which cue and context are usually not easily separated. The conditioning chamber consisted of a brightly lit plexiglass box $(25 \times 29 \times 29 \mathrm{~cm})$ with stainless steel-grid floor that was enclosed within a sound-attenuating box (Coulbourn Instruments, Whitehall, PA).

Experiment 1. Rats were first habituated to the chamber for 5 min on 2 consecutive days. The following day (day 1 ), rats were conditioned. Conditioning involved $2 \mathrm{~min}$ of acclimation to the chamber after which rats received a single pairing of a tone $(30 \mathrm{~s}, 5 \mathrm{kHz}, 75 \mathrm{~dB})$ coterminating with a foot shock ( $1 \mathrm{~s}, 0.75 \mathrm{~mA})$. Rats remained in the chamber an additional minute before being returned to their home cages. On day 2 , the fear memory was reactivated by placing the animals in the experimental chamber and presenting the tone without the shock. Rats were then removed from the context and clonidine $(50,100$, or $200 \mu \mathrm{g} / \mathrm{kg})$ or its vehicle was administered immediately. On days 3 and 10, animals were tested for postreactivation long-term memory (PRLTM) with the presentation of a single tone.

Experiment 2. Nonreactivated controls were habituated and trained as in experiment 1 , but rats did not receive the reactivation and instead remained in the animal colony where they received the clonidine treatment on day 2 .

Experiment 3. As a postreactivation short-term memory (PR-STM) control, animals were habituated, trained, reactivated, and given postreactivation clonidine as in experiment 1 . They were tested $4 \mathrm{~h}$ after the reactivation session on day 2 , and again $24 \mathrm{~h}$ later.

Experiment 4. Rats underwent the same procedure as in experiment 1 and received clonidine $(200 \mu \mathrm{g} / \mathrm{kg})$ or vehicle following reactivation. After the test on day 10, rats were allowed 2 days of rest before undergoing habituation, new conditioning, and testing in a different experimental chamber. The conditioning chamber consisted of a dimly lit plexiglass and steel box $(25 \times 29 \times 29 \mathrm{~cm})$ with one curved white plastic wall and one black and white striped wall, enclosed within a sound-attenuating box (Med Associates, VT). A smaller steel-grid floor was used in this design and peppermint-scented water was also vaporized 
inside the box to create a different scent than before. Rats were first habituated to the chamber for $5 \mathrm{~min}$ on 2 consecutive days. The following day (day 14), rats were newly conditioned. After 3 and a half minutes of acclimation to the chamber, rats received a single pairing of a different frequency tone $(20 \mathrm{~s}, 3 \mathrm{kHz}, 85 \mathrm{~dB})$ coterminating with a foot shock $(1 \mathrm{~s}, 1.1 \mathrm{~mA})$. Rats remained in the chamber an additional 2 min before being returned to their home cages.

Experiment 5. Rats were habituated, trained, and reactivated as described in experiment 1 . However, rats underwent reactivation on days 2,3 , and 4 , each time followed by an injection of clonidine $(100 \mu \mathrm{g} / \mathrm{kg})$ or its vehicle. Rats were tested on days 5 and 12 using the same procedure as above.

Behavior was recorded using FreezeView software (Actimetrics). Freezing, defined as immobilization with the exception of respiration (Blanchard and Blanchard, 1969), was the conditioned response taken as a measure of fear memory retention. Scores are presented as the percentage of time spent freezing during the total duration of the tone.

\section{Statistical Analysis}

A repeated-measures analysis of variance (ANOVA) followed by Fisher's post hoc analysis was used to compare groups across days. Significance was set as $p<0.05$.

\section{RESULTS}

For all experiments, no significant sex main effect or interaction was observed for freezing to the tone. A repeatedmeasures ANOVA across days revealed no difference in freezing scores between males and females for any experiment. This lack of sex differences allowed us to combine the freezing scores for males and females for each experiment.
Pre-tone freezing was also analyzed with a repeatedmeasures ANOVA across days and no significant main effect of treatment or interaction was observed for any of the experiments. A main effect of sex was observed on pretone freezing only for experiments 1 and 3, where there was a lower pre-tone freezing response in the females. In light of these isolated results, the lack of treatment effect on pretone freezing, and because our measure of memory retention was tone-related freezing, pre-tone freezing was not further investigated.

\section{Experiment 1: Postreactivation Administration of Clonidine Impairs Reconsolidation of Auditory Fear Memories in a Dose-Dependent Manner}

We evaluated whether clonidine is effective at disrupting fear memory reconsolidation when administered systemically at 50,100 , or $200 \mu \mathrm{g} / \mathrm{kg}$. We conditioned the animals on day 1 and reactivated them the following day by exposing them again to the conditioning chamber and the tone. After reactivation, animals received an injection of clonidine or its vehicle and were tested for memory retention a day later. To establish if the effects of clonidine were long lasting, rats were also tested again on day 10 (Figure 1a). Clonidine was effective at blocking memory reconsolidation at all tested doses, and its effect was long lasting as the memory impairment was still observed a week after the treatment (Figure $1 \mathrm{~b}-\mathrm{d}$ ). A repeated-measures ANOVA revealed a main effect of treatment $(\mathrm{F}(1,34)=6.08$, $p<0.05$ for $50 \mu \mathrm{g} / \mathrm{kg} ; \mathrm{F}(1,48)=10.61, p<0.01$ for $100 \mu \mathrm{g} / \mathrm{kg}$; $\mathrm{F}(1,37)=7.99, p<0.01$ for $200 \mu \mathrm{g} / \mathrm{kg})$ and day $(\mathrm{F}(2,68)=$ 9.09, $p<0.001$ for $50 \mu \mathrm{g} / \mathrm{kg} ; \mathrm{F}(2,96)=36.04, p<0.001$ for $100 \mu \mathrm{g} / \mathrm{kg} ; \mathrm{F}(2,74)=22.05, p<0.0001$ for $200 \mu \mathrm{g} / \mathrm{kg})$. A significant treatment $\times$ day interaction was observed for $100 \mu \mathrm{g} / \mathrm{kg}(\mathrm{F}(2,96)=4.66, p<0.05)$ and $200 \mu \mathrm{g} / \mathrm{kg}$ $(\mathrm{F}(2,74)=5.71, p<0.01)$. Subsequent Fisher's post hoc tests indicated significant differences between the clonidinetreated group and the controls at both memory retention

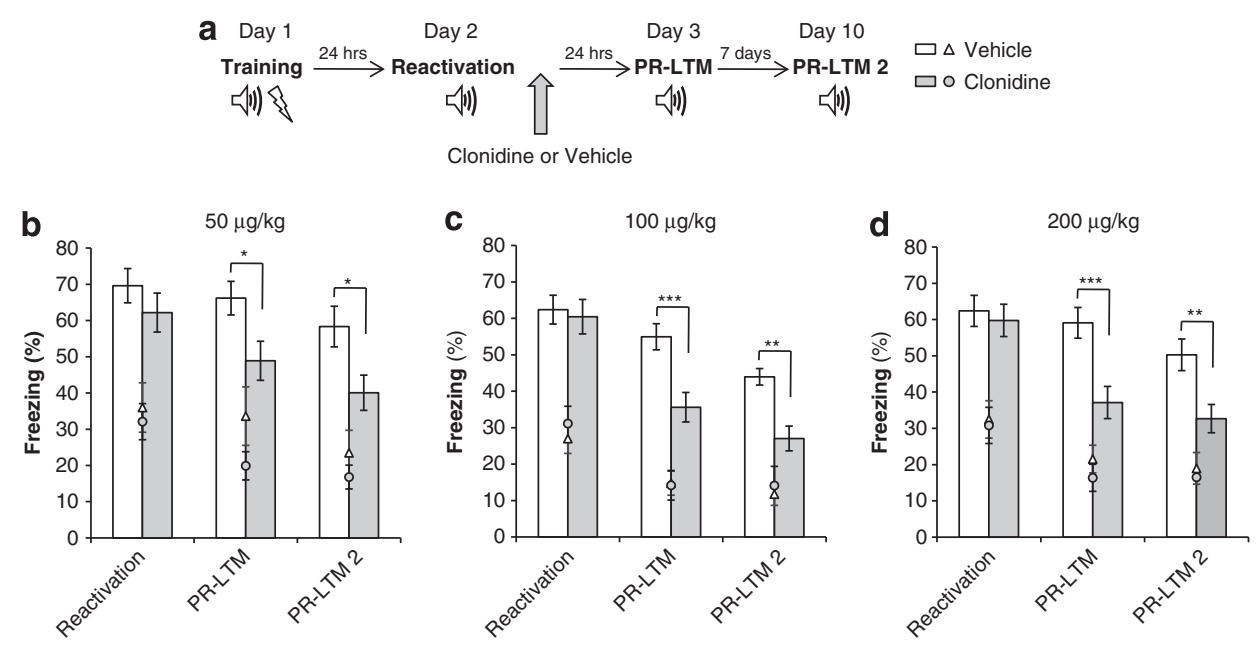

Figure I Postreactivation administration of clonidine impairs reconsolidation of auditory fear memories. (a) Schematic of the experimental design. Rats received a single systemic injection of clonidine or its vehicle immediately after a reactivation session, and were tested for postreactivation long-term memory I day (PR-LTM) and I week later (PR-LTM 2). A dose of (b) $50 \mu \mathrm{g} / \mathrm{kg}(n=20)$, (c) $100 \mu \mathrm{g} / \mathrm{kg}(n=25)$ and (d) $200 \mu \mathrm{g} / \mathrm{kg}(n=20)$ was effective at impairing memory reconsolidation compared with the vehicle group (respectively, $n=16, n=25$, and $n=20$ ) as shown by an impaired conditioned response (freezing) at both time points. Bars represent mean \pm SEM freezing to the tone. Markers represent the mean \pm SEM freezing before the onset of the tone. Statistical significance: $* p<0.05$, $* * p<0.01$, $* * * * 0.001$. 
tests (for $50 \mu \mathrm{g} / \mathrm{kg}, p<0.05$ for both tests; for $100 \mu \mathrm{g} / \mathrm{kg}$, $p<0.001$ for PR-LTM and $p<0.01$ for PR-LTM 2; for $200 \mu \mathrm{g} /$ $\mathrm{kg}, p<0.001$ for PR-LTM and $p<0.01$ for PR-LTM 2). In addition, significant freezing decreases were observed within the clonidine group between reactivation and both PR-LTM performances (for $50 \mu \mathrm{g} / \mathrm{kg}, p<0.05$; for $100 \mu \mathrm{g} / \mathrm{kg}$, $p<0.001$; for $200 \mu \mathrm{g} / \mathrm{kg}, p<0.001)$. Taken together, the present data suggest that clonidine disrupted fear memory reconsolidation in a dose-dependent manner. Clonidine reached its maximum effect at $100 \mu \mathrm{g} / \mathrm{kg}$, as increasing the dose further did not lead to a greater impairment of the conditioned response in the treated group.

\section{Experiment 2: Reconsolidation Blockade by Clonidine Is Selective to Reactivated Fear Memories}

We assessed whether the effect of clonidine on reconsolidation was dependent on memory reactivation. We injected clonidine at a dose of $100 \mu \mathrm{g} / \mathrm{kg} 24 \mathrm{~h}$ after training without exposing the animals to the conditioning chamber and tone. Rats were tested for memory retention on days 3 and 10 (Figure 2a). No significant effect of clonidine (repeatedmeasures ANOVA, $F(1,22)=0.002, p>0.05)$ was observed in the absence of reactivation, as compared with the vehicleinjected group 1 day and 1 week after receiving the treatment (Figure 2b). In addition, a repeated-measures ANOVA showed no significant effect of day $(\mathrm{F}(1,22)=1.34$, $p>0.05)$ and no treatment $\times$ day interaction $(F(1,22)=$ $0.39, p>0.05)$. Thus, clonidine disrupts reconsolidation of an auditory fear memory only when administered following reactivation of that memory.
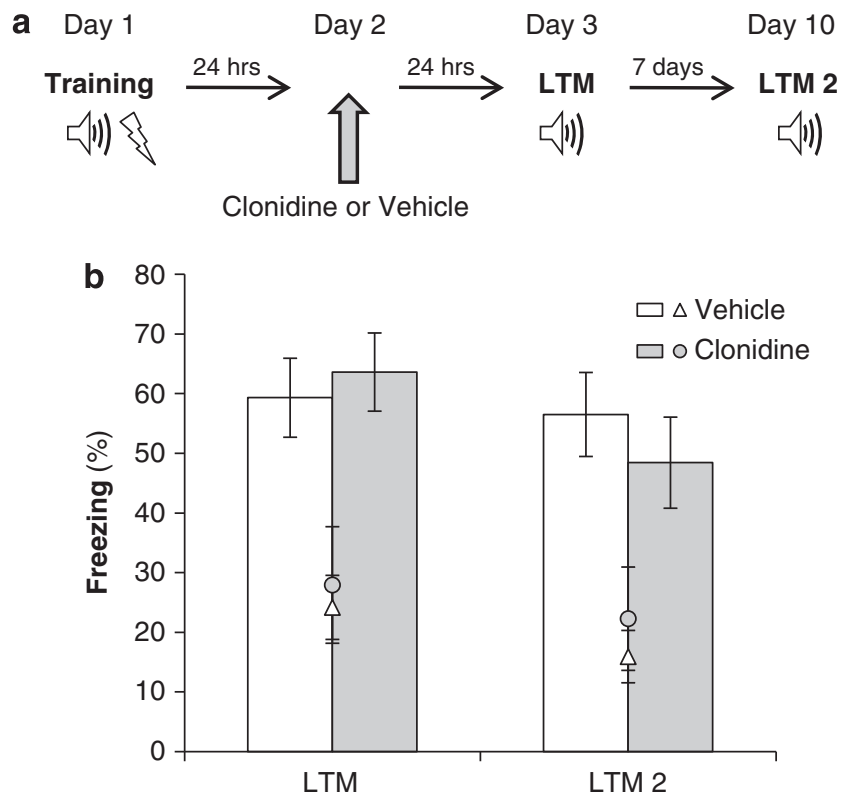

Figure 2 Clonidine does not impair retention of nonreactivated fear memories. (a) Schematic of the experimental design. Rats received a single systemic injection of clonidine $(100 \mu g / k g)$ or its vehicle without a memory reactivation session and were tested for long-term memory retention I day (LTM) and I week later (LTM 2). (b) Clonidine-treated rats $(n=12)$ showed a similar conditioned response (freezing) to the vehicle group $(n=12)$ when tested $24 \mathrm{~h}$ or I week after injection. Bars represent mean \pm SEM freezing to the tone. Markers represent the mean \pm SEM freezing before the onset of the tone.
Experiment 3: Postreactivation Administration of Clonidine Does Not Impair Short-Term Fear Memories

To rule out the possibility that nonspecific effects of postreactivation clonidine create temporary dysfunctions of the memory system, we trained and reactivated rats as described before. After reactivation, animals received $100 \mu \mathrm{g} / \mathrm{kg}$ of clonidine or vehicle and were tested for memory retention 4 and $24 \mathrm{~h}$ later (Figure 3a). If the memory impairment seen at PR-LTM is due to reconsolidation blockade, then animals should show an intact conditioned response $4 \mathrm{~h}$ after reactivation (PR-STM) but reduced freezing behavior $24 \mathrm{~h}$ later (PR-LTM). A repeatedmeasures ANOVA showed a significant main effect of treatment $(\mathrm{F}(1,19)=5.49, p<0.05)$ and day $(\mathrm{F}(2,38)=10.9$, $p<0.001)$, but no treatment $\times$ day interaction $(\mathrm{F}(2,38)=$ $2.21, p>0.05$; Figure $3 \mathrm{~b}$ ). Nevertheless, Fisher's post hoc test revealed a similar conditioned response for the clonidinetreated rats as compared with the vehicle group at PR-STM $(p>0.05)$ but showed a significant decrease in freezing for the clonidine group at PR-LTM as compared with PR-STM $(p<0.001)$ and to controls at PR-LTM $(p<0.001)$. Hence, the results confirm that postretrieval clonidine selectivity disrupts reconsolidation of long-term memories.

\section{Experiment 4: Reconsolidation Blockade by Clonidine Does Not Impair the Ability to Learn New Fear Memories}

To evaluate whether postreactivation clonidine could induce permanent learning impairments, we conditioned animals to fear a different tone using a different auditory
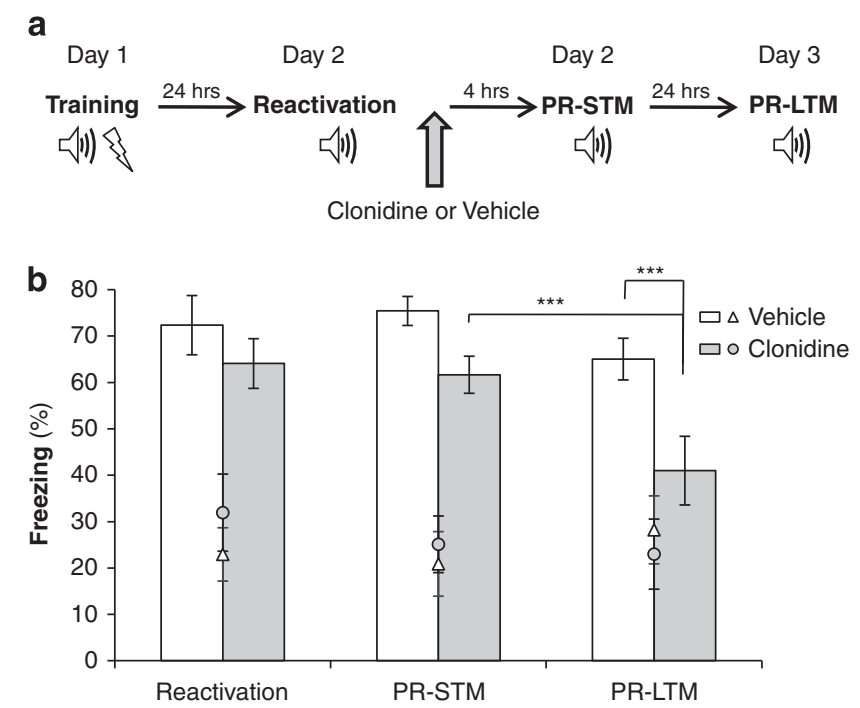

Figure 3 Postreactivation administration of clonidine does not impair short-term fear memories. (a) Schematic of the experimental design. Rats received a single systemic injection of clonidine $(100 \mu \mathrm{g} / \mathrm{kg})$ or its vehicle immediately after a reactivation session and were tested $4 \mathrm{~h}$ later for postreactivation short-term memory (PR-STM) and I day later for postreactivation long-term memory (PR-LTM). (b) Clonidine-treated rats $(n=12)$ showed a similar conditioned response (freezing) to the vehicle group $(n=9)$ when tested $4 \mathrm{~h}$ after reactivation, but reduced freezing behavior I day after injection. Bars represent mean \pm SEM freezing to the tone. Markers represent the mean \pm SEM freezing before the onset of the tone. Statistical significance: $*^{*} * * 0.001$. 
fear protocol. After receiving a postreactivation injection of clonidine $(200 \mu \mathrm{g} / \mathrm{kg})$ or vehicle, and a memory retention test 1 and 7 days later, rats were trained again and tested for memory of the new tone (Figure 4a). The highest dose was chosen for this experiment to ensure that if no impairments were observed, it could not be attributed to the use of a low concentration. We hypothesized that if the clonidine-related memory impairment is selective to reconsolidation blockade, then the fear response of the previously treated animals should be similar to the controls when tested for memory of the new tone. A repeated-measures ANOVA revealed no significant main effect of treatment $(\mathrm{F}(1,22)=0.002$, $p>0.05)$, day $(\mathrm{F}(1,22)=2.17, p>0.05)$, and no treatment $\times$ day interaction $(\mathrm{F}(1,22)=0.7, p>0.05$; Figure $4 \mathrm{~b})$. As both groups exhibited similar levels of conditioned response on the two test days, our data indicate that administering clonidine after reactivation does not induce a long-lasting, generalized fear learning impairment.

\section{Experiment 5: Two Postretrieval Treatments of Clonidine Are Sufficient to Induce Maximal Disruption of Fear Memories}

To assess whether a greater memory impairment could be achieved using a dose of $100 \mu \mathrm{g} / \mathrm{kg}$, we trained animals as described before but we reactivated them 3 times over 3 days. Following each reactivation session, rats received an injection of clonidine or its vehicle. Rats were also tested $24 \mathrm{~h}$ after the last treatment and 1 week later (Figure 5a). A repeatedmeasures ANOVA revealed a significant main effect of treatment $(\mathrm{F}(4,116)=9.91, p<0.01)$ and day $(\mathrm{F}(4,116)$ $=26.04, \quad p<0.001)$, and a treatment $\times$ day interaction $(\mathrm{F}(4,116)=2.70, p<0.05)$. Fisher's post hoc test found a significant decrease in conditioned response for the clonidine-treated group between reactivations 1 and $2(\mathrm{~F}(4,116)$ $=26.04, p<0.001)$ and reactivations 2 and $3(\mathrm{~F}(4,116)=$ 26.04, $p<0.05$; Figure 5b). Although the third treatment showed a trend toward additional freezing reduction, it did not have a significant additive effect. The post hoc analysis also revealed a significant difference between the treated rats and the controls at days 2, 3, 4, and 12 (all $p<0.01$ ). Altogether, the results indicate that reconsolidation blockade by clonidine was effective after one treatment and reached its maximum effect after two treatments.

\section{DISCUSSION}

This study demonstrates the effectiveness of clonidine in persistently impairing fear memory retention through reconsolidation blockade in male and female rats. We suggest that the combination of memory reactivation sessions followed by clonidine administration represent a potentially novel therapeutic approach to reduce symptoms in PTSD patients.

\section{Dosage and Number of Treatments}

All tested doses of clonidine showed effectiveness in reducing postreactivation fear memory retention in a long-lasting and dose-dependent manner. The dose of $100 \mu \mathrm{g} / \mathrm{kg}$ was determined to be optimally effective because it resulted in a greater memory impairment from reactivation to the PR-LTM test than did the $50 \mu \mathrm{g} / \mathrm{kg}$ dose. However, the dose of $200 \mu \mathrm{g} / \mathrm{kg}$ did not induce a larger reduction in freezing than the $100 \mu \mathrm{g} / \mathrm{kg}$ dose, which suggests that the dose-response curve reaches a plateau, and increasing the dose further will not lead to a more substantial decrease in conditioned responding. On the other hand, we did find that the fear memory could be disrupted further with repeated treatments. Indeed, we established that two reactivation sessions followed by a $100 \mu \mathrm{g} / \mathrm{kg}$ clonidine administration were sufficient to induce maximal memory disruption.

a
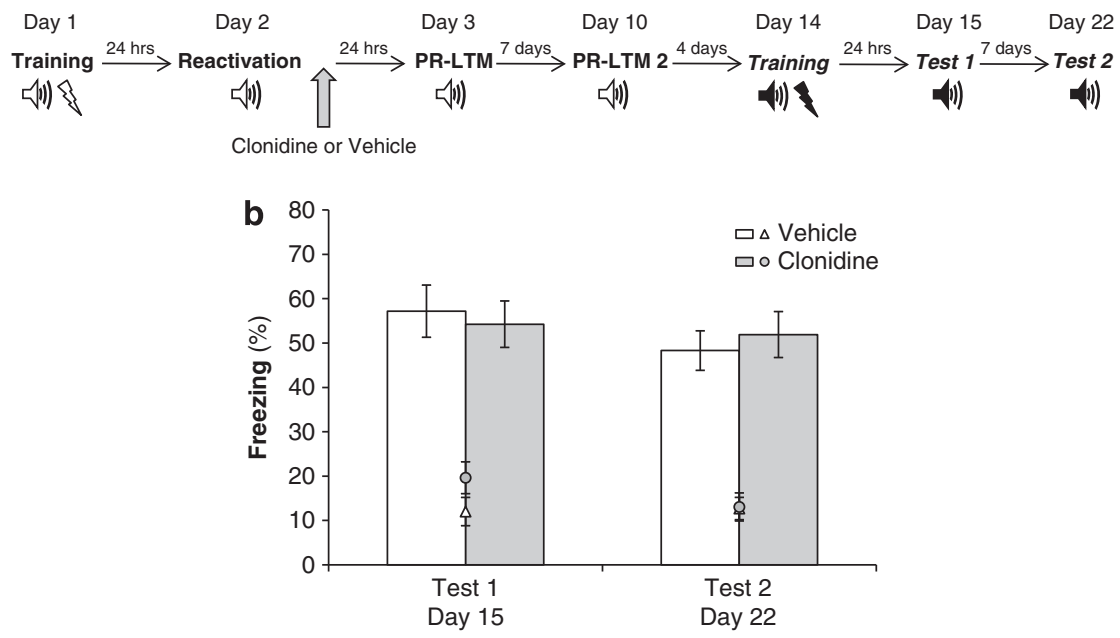

Figure 4 Postreactivation administration of clonidine does not impair the ability to learn new fear memories. (a) Schematic of the experimental design. After receiving a postreactivation injection of clonidine $(200 \mu \mathrm{g} / \mathrm{kg})$ or vehicle, and being tested for memory retention I day (PR-LTM) and I week later (PRLTM 2), rats were conditioned to fear a different tone using a different auditory fear protocol. (b) Rats that previously received clonidine $(n=12)$ showed intact fear behavior (freezing) compared with the vehicle-treated animals $(n=12)$ when tested I day (test I) or I week later (test 2). Bars represent mean \pm SEM freezing to the tone. Markers represent the mean \pm SEM freezing before the onset of the tone. 


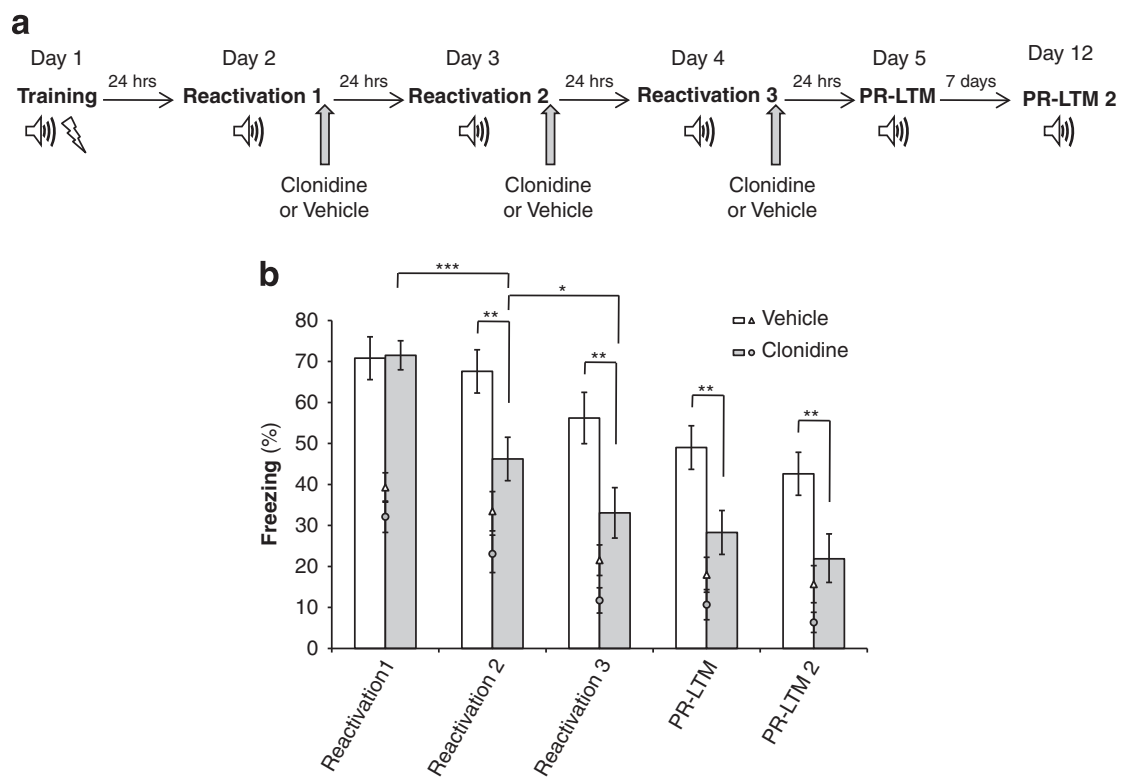

Figure 5 Two postreactivation clonidine treatments are sufficient to maximally impair fear memory retention. (a) Schematic of the experimental design. Rats received a systemic injection of clonidine $(100 \mu \mathrm{g} / \mathrm{kg})$ or its vehicle immediately after a reactivation session for 3 consecutive days and were tested for postreactivation long-term memory I day (PR-LTM) and I week later (PR-LTM 2). (b) Clonidine-treated rats $(n=16)$ showed an impaired conditioned response (freezing) as compared with the vehicle group $(n=15)$ at each test session. Memory disruption was observed after the first clonidine treatment and reached its maximum after two treatments at day 3 . Bars represent mean \pm SEM freezing to the tone. Markers represent the mean \pm SEM freezing before the onset of the tone. Statistical significance: $* x<0.05$, *** $p<0.01$, $* * * * 0.001$.

Our results are consistent with studies showing that clonidine has detrimental effects on memory. In animals, clonidine has been found to produce memory impairments in several learning paradigms ranging from shuttle box (Hawkins and Monti, 1979; Homayoun et al, 2003) to avoidance tasks (Galeotti et al, 2004; Genkova-Papasova and Lazarova-Bakurova, 1988; Genkova-Papazova et al, 1997) and to cue detection (Smith and Aston-Jones, 2011; Brown et al, 2012). Some studies in humans have also reported memory impairments associated with clonidine administration in healthy subjects (Riekkinen et al, 1999; Hall et al, 2001) and in Alzheimer's disease patients (Jakala et al, 1999a, b).

It is well known that $\alpha_{2}$-adrenoreceptor agonists can induce sedation (Lakhlani et al, 1997; MacDonald et al, 1997). However, the possibility that a sedative effect of clonidine influenced the behavioral results in our study can be ruled out as we tested the animals $24 \mathrm{~h}$ and again 7 days after injection, the time points well beyond the 30-120 min half-life of clonidine in rats (Conway and Jarrott, 1982).

\section{Reconsolidation Specificity}

We have shown that postretrieval administration of clonidine is effective in reducing fear-related memory retention. In order to confirm whether reconsolidation is the mechanism underlying the effect, we examined key elements that define the reconsolidation process. First, our results demonstrate that the effect of clonidine is selective to the reactivated memory, as no memory impairment was observed when clonidine was administered without prior reactivation. Furthermore, when animals were tested a week after treatment, we did not observe any spontaneous recovery of the conditioned response. Spontaneous recovery is a phenomenon found with extinguished memories, but not after reconsolidation blockade (Duvarci and Nader, 2004). As reconsolidation is a time-dependent process that is known to affect long-term but not short-term memory (Nader et al, 2000; Nader and Hardt, 2009), we also tested the animals $4 \mathrm{~h}$ after reactivation. The results revealed an intact conditioned response at that time point but impaired behavior the next day. This demonstrates that clonidine affects postreactivation long-term memory, but not short-term memory. Given that this test was performed only $4 \mathrm{~h}$ after clonidine administration, one could argue that the sedative effects of clonidine altered the results at this shorter interval after drug administration. However, the treated rats displayed low levels of freezing during the pre-tone period, indicating an ability to move; thus, the intact freezing levels observed at PR-STM after clonidine administration are unlikely to be attributable to motor impairments due to sedation in these animals. In addition, it is reasonable to believe that the drug was no longer present in the rats' systems at the time of testing because clonidine has a short half-life (30-120 min; Conway and Jarrott, 1982).

Evaluation of the above-mentioned criteria all rule in favor of the implication of reconsolidation processes in the present study. Our results are consistent with several studies investigating reconsolidation blockers either systemically (Debiec and Ledoux, 2004; Blundell et al, 2008; Taubenfeld et al, 2009; Pitman et al, 2011) or intracranially (Nader et al, 2000; Debiec and Ledoux, 2004; Ben Mamou et al, 2006; Jin et al, 2007). Indeed, it is accepted in the literature that the lack of spontaneous recovery, the selectivity to reactivated memories, and the presence of intact short-term memory are criteria that define the reconsolidation process. Taken together, our results suggest that the effect of clonidine on memory is mediated by reconsolidation blockade. 


\section{Clinical Relevance}

Currently, there are no specific pharmacological approaches to treat PTSD symptoms. Therefore, there is a need for preclinical research to identify new candidate drugs and to develop novel therapeutic interventions. The present study has implications for the potential clinical use of reconsolidation blockade by clonidine. First, we determined that the dose of $100 \mu \mathrm{g} / \mathrm{kg}$ optimally disrupts fear memory retention in both male and female rats. Conversion from the animal dose to a human equivalent dose in $\mathrm{mg} / \mathrm{kg}$ may be obtained by applying a formula that takes the body surface area into account. With this calculation, our animal dosage of $100 \mu \mathrm{g} /$ $\mathrm{kg}$ translates into a dose of $1.135 \mathrm{mg}$ for a $70-\mathrm{kg}$ person (Reagan-Shaw et al, 2008). Such a dose is well within the safe range for daily human use that has a maximum of $2.4 \mathrm{mg}$ (Physician's Desk Reference; http://www.pdr.net). Nevertheless, as clonidine is known to induce hypotension, patients being treated with clonidine should be medically monitored. We also found that clonidine-induced memory impairments are selective to the reactivated memory. Thus, we can hypothesize that using clonidine in combination with traumatic memory reactivation will decrease the intensity of that memory without disrupting other unrelated memories. Additionally, we observed that postreactivation clonidine does not affect learning of new fear memories, implying that patients would be able to experience and remember new events normally. These are all valuable aspects for clinical use, as optimal treatments should be specific and not interfere with other processes (Steckler and Risbrough, 2011).

Clonidine has been found to improve symptoms such as hyperarousal (Harmon and Riggs, 1996; Donnelly, 2003), impulsivity (Donnelly, 2003) (Viola et al, 1997), and nightmares (Kinzie and Leung, 1989; Kinzie et al, 1994) when administered chronically to patients. However, some experienced a return of symptoms upon termination of treatment (Porter and Bell, 1999), and the possibility that the beneficial effects would decrease over time remains. A significant advantage of reconsolidation blockade by clonidine in treating PTSD symptoms would be that it does not require chronic administration of the drug, as based upon our animal findings the maximal effect would probably be obtained within a few sessions. Consequently, this would make lasting side effects unlikely. Furthermore, we showed that memory disruption following postretrieval clonidine is long lasting; thus, it is reasonable to hope that combining memory reactivation with clonidine administration could permanently weaken PTSD symptoms such as intrusive memories without the possibility of relapse.

Although fear conditioning models the enhanced fear response upon recollection of the traumatic event, this is only one of the many pathophysiological and behavioral characteristics of PTSD. Nightmares, avoidance, and hyperarousal are common, and alterations of several neurotransmitter systems have also been observed. Further investigations will be necessary to verify whether clonidine can improve other aspects of this complex pathology in an animal model.

In conclusion, results of this study demonstrate that systemic administration of clonidine after retrieval persistently weakens fear memories through reconsolidation blockade. We show that this effect is maximal after two treatments, is present in both male and female rats, is selective to the reconsolidation time window and to reactivated memories, and does not affect further fear learning. These preclinical findings indicate potential to further develop clinical approaches using clonidine as a reconsolidation blocker in the treatment of PTSD symptoms.

\section{ACKNOWLEDGEMENTS}

This work was supported by USARAA grant W81XWH-082-0126 (PT075809).

\section{DISCLOSURE}

The authors declare no conflict of interest.

\section{REFERENCES}

Ben Mamou C, Gamache K, Nader K (2006). NMDA receptors are critical for unleashing consolidated auditory fear memories. Nat Neurosci 9: 1237-1239.

Berger W, Mendlowicz MV, Marques-Portella C, Kinrys G, Fontenelle LF, Marmar CR et al (2009). Pharmacologic alternatives to antidepressants in posttraumatic stress disorder: a systematic review. Prog Neuropsychopharmacol Biol Psychiatry 33: $169-180$.

Blanchard RJ, Blanchard DC (1969). Passive and active reactions to fear-eliciting stimuli. J Comp Physiol Psychol 68: 129-135.

Blundell J, Kouser M, Powell CM (2008). Systemic inhibition of mammalian target of rapamycin inhibits fear memory reconsolidation. Neurobiol Learn Mem 90: 28-35.

Boehnlein JK, Kinzie JD (2007). Pharmacologic reduction of CNS noradrenergic activity in PTSD: the case for clonidine and prazosin. J Psychiatr Pract 13: 72-78.

Brown 2nd DC, Co MS, Wolff RC, Atzori M (2012). alphaAdrenergic receptors in auditory cue detection: alpha(2) receptor blockade suppresses false alarm responding in the rat. Neuropharmacology 62: 2178-2183.

Charney DS (2004). Psychobiological mechanisms of resilience and vulnerability: implications for successful adaptation to extreme stress. Am J Psychiatry 161: 195-216.

Conway EL, Jarrott B (1982). Tissue pharmacokinetics of clonidine in rats. J Pharmacokinet Biopharm 10: 187-200.

Davidson J, Rothbaum BO, Tucker P, Asnis G, Benattia I, Musgnung JJ (2006). Venlafaxine extended release in posttraumatic stress disorder: a sertraline- and placebo-controlled study. J Clin Psychopharmacol 26: 259-267.

Debiec J, Ledoux JE (2004). Disruption of reconsolidation but not consolidation of auditory fear conditioning by noradrenergic blockade in the amygdala. Neuroscience 129: 267-272.

Donnelly CL (2003). Pharmacologic treatment approaches for children and adolescents with posttraumatic stress disorder. Child Adolesc Psychiatr Clin N Am 12: 251-269.

Duvarci S, Nader K (2004). Characterization of fear memory reconsolidation. J Neurosci 24: 9269-9275.

Galeotti N, Bartolini A, Ghelardini C (2004). Alpha-2 agonistinduced memory impairment is mediated by the alpha-2Aadrenoceptor subtype. Behav Brain Res 153: 409-417.

Genkova-Papasova M, Lazarova-Bakurova M (1988). Influence of nootropic drugs on the memory-impairing effect of diethyldithiocarbamate and clonidine in "step down" passive avoidance in albino rats. Acta Physiol Pharmacol Bulg 14: 36-41.

Genkova-Papazova M, Petkova BP, Lazarova-Bakarova M, Boyanova E, Staneva-Stoytcheva D (1997). Effects of flunarizine and 
nitrendipine on electroconvulsive shock- and clonidine-induced amnesia. Pharmacol Biochem Behav 56: 583-587.

Gilsbach R, Hein L (2011). Are the pharmacology and physiology of alpha(2)-adrenoceptors determined by alpha(2)-heteroreceptors and autoreceptors, respectively? $\mathrm{Br} J$ Pharmacol 165: 90-102.

Hall JE, Uhrich TD, Ebert TJ (2001). Sedative, analgesic and cognitive effects of clonidine infusions in humans. Br J Anaesth 86: 5-11.

Harmon RJ, Riggs PD (1996). Clonidine for posttraumatic stress disorder in preschool children. J Am Acad Child Adolesc Psychiatry 35: 1247-1249.

Hawkins M, Monti JM (1979). Effects of pretreatment with 6hydroxydopamine or noradrenergic receptor blockers on the clonidine-induced distruption of conditioned avoidance responding. Eur J Pharmacol 58: 53-58.

Homayoun H, Khavandgar S, Zarrindast MR (2003). Morphine state-dependent learning: interactions with alpha2-adrenoceptors and acute stress. Behav Pharmacol 14: 41-48.

Jakala P, Riekkinen M, Sirvio J, Koivisto E, Kejonen K, Vanhanen $M$ et al (1999a). Guanfacine, but not clonidine, improves planning and working memory performance in humans. Neuropsychopharmacology 20: 460-470.

Jakala P, Riekkinen M, Sirvio J, Koivisto E, Riekkinen Jr P (1999b). Clonidine, but not guanfacine, impairs choice reaction time performance in young healthy volunteers. Neuropsychopharmacology 21: 495-502.

Jin XC, Lu YF, Yang XF, Ma L, Li BM (2007). Glucocorticoid receptors in the basolateral nucleus of amygdala are required for postreactivation reconsolidation of auditory fear memory. Eur $J$ Neurosci 25: 3702-3712.

Jobim PF, Pedroso TR, Christoff RR, Werenicz A, Maurmann N, Reolon GK et al (2012). Inhibition of mTOR by rapamycin in the amygdala or hippocampus impairs formation and reconsolidation of inhibitory avoidance memory. Neurobiol Learn Mem 97: 105-112.

Kessler RC, Berglund P, Demler O, Jin R, Merikangas KR, Walters EE (2005). Lifetime prevalence and age-of-onset distributions of DSM-IV disorders in the National Comorbidity Survey Replication. Arch Gen Psychiatry 62: 593-602.

Kinzie JD, Leung P (1989). Clonidine in Cambodian patients with posttraumatic stress disorder. J Nerv Ment Dis 177: 546-550.

Kinzie JD, Sack RL, Riley CM (1994). The polysomnographic effects of clonidine on sleep disorders in posttraumatic stress disorder: a pilot study with Cambodian patients. J Nerv Ment Dis 182: 585-587.

Lakhlani PP, MacMillan LB, Guo TZ, McCool BA, Lovinger DM, Maze $M$ et al (1997). Substitution of a mutant alpha2aadrenergic receptor via "hit and run" gene targeting reveals the role of this subtype in sedative, analgesic, and anestheticsparing responses in vivo. Proc Natl Acad Sci USA 94: 9950-9955.

MacDonald E, Kobilka BK, Scheinin M (1997). Gene targetinghoming in on alpha 2-adrenoceptor-subtype function. Trends Pharmacol Sci 18: 211-219.

MacMillan LB, Hein L, Smith MS, Piascik MT, Limbird LE (1996). Central hypotensive effects of the alpha2a-adrenergic receptor subtype. Science 273: 801-803.
Nader K, Hardt O (2009). A single standard for memory: the case for reconsolidation. Nat Rev Neurosci 10: 224-234.

Nader K, Schafe GE, Le Doux JE (2000). Fear memories require protein synthesis in the amygdala for reconsolidation after retrieval. Nature 406: 722-726.

Onder E, Tural U, Aker T (2006). A comparative study of fluoxetine, moclobemide, and tianeptine in the treatment of posttraumatic stress disorder following an earthquake. Eur Psychiatry 21: 174-179.

Pitman RK, Milad MR, Igoe SA, Vangel MG, Orr SP, Tsareva A et al (2011). Systemic mifepristone blocks reconsolidation of cue-conditioned fear; propranolol prevents this effect. Behav Neurosci 125: 632-638.

Pitman RK, Orr SP, Shalev AY, Metzger LJ, Mellman TA (1999). Psychophysiological alterations in post-traumatic stress disorder. Semin Clin Neuropsychiatry 4: 234-241.

Porter DM, Bell CC (1999). The use of clonidine in post-traumatic stress disorder. J Natl Med Assoc 91: 475-477.

Przybyslawski J, Roullet P, Sara SJ (1999). Attenuation of emotional and nonemotional memories after their reactivation: role of beta adrenergic receptors. J Neurosci 19: 6623-6628.

Reagan-Shaw S, Nihal M, Ahmad N (2008). Dose translation from animal to human studies revisited. FASEB J 22: 659-661.

Riekkinen M, Laakso MP, Jakala P (1999). Clonidine impairs sustained attention and memory in Alzheimer's disease. Neuroscience 92: 975-982.

Siegmund A, Wotjak CT (2006). Toward an animal model of posttraumatic stress disorder. Ann NY Acad Sci 1071: 324-334.

Smith RJ, Aston-Jones G (2011). Alpha(2) Adrenergic and imidazoline receptor agonists prevent cue-induced cocaine seeking. Biol Psychiatry 70: 712-719.

Southwick SM, Bremner JD, Rasmusson A, Morgan 3rd CA, Arnsten A, Charney DS (1999). Role of norepinephrine in the pathophysiology and treatment of posttraumatic stress disorder. Biol Psychiatry 46: 1192-1204.

Southwick SM, Morgan 3rd CA, Bremner AD, Grillon CG, Krystal JH, Nagy LM et al (1997). Noradrenergic alterations in posttraumatic stress disorder. Ann NY Acad Sci 821: 125-141.

Steckler T, Risbrough V (2011). Pharmacological treatment of PTSD-established and new approaches. Neuropharmacology 62: 617-627.

Taubenfeld SM, Riceberg JS, New AS, Alberini CM (2009). Preclinical assessment for selectively disrupting a traumatic memory via postretrieval inhibition of glucocorticoid receptors. Biol Psychiatry 65: 249-257.

Viola J, Ditzler T, Batzer W, Harazin J, Adams D, Lettich L et al (1997). Pharmacological management of post-traumatic stress disorder: clinical summary of a five-year retrospective study, 1990-1995. Mil Med 162: 616-619.

Wilens TE (2006). Mechanism of action of agents used in attention-deficit/hyperactivity disorder. J Clin Psychiatry 67 (Suppl 8): 32-38.

Ziegenhorn AA, Roepke S, Schommer NC, Merkl A, Danker-Hopfe $\mathrm{H}$, Perschel FH et al (2009). Clonidine improves hyperarousal in borderline personality disorder with or without comorbid posttraumatic stress disorder: a randomized, double-blind, placebo-controlled trial. J Clin Psychopharmacol 29: 170-173. 